\title{
Reflux Symptoms: Can We Sort Them Out?
}

\author{
K.R. Devault \\ Mayo Clinic, Jacksonville, Fla., USA
}

Empirical therapy plays an important role in most algorithms and guidelines for the diagnosis and therapy of gastroesophageal reflux disease (GERD), including the most recent guidelines produced by the American College of Gastroenterology (ACG) and endorsed by the other major societies [1]. The ACG guidelines state, 'If the patient's history is typical for uncomplicated GERD, an initial trial of empirical therapy, including lifestyle modification is appropriate'. This assumes that clinicians are able to do two things: (1) determine that a history is typical for GERD, and (2) rule out GERD complications by taking that history.

It is commonly understood that the combination of heartburn and regurgitation, often made worse by large or fatty meals, recumbency or bending over, is highly suggestive of GERD. Patients who have these symptoms and also have endoscopic changes of esophagitis unquestionably have GERD [2]. The more important question is, 'are these symptoms specific for GERD in the unendoscoped patient?' A large Scandinavian study evaluated symptoms using a standardized questionnaire and abnormal $\mathrm{pH}$ monitoring or endoscopic changes as the gold standard. They found that a symptom assessment had a good sensitivity $(92 \%)$, but very poor specificity $(19 \%)$ [3]. A previous study found that the daily occurrence of heartburn or acid regurgitation only had positive predictive values of 59 and $66 \%$ compared to objective measures of pathologic reflux [4].

A therapeutic trial may be a 'diagnostic' maneuver that improves our ability to diagnose reflux without invasive testing. With regard to noncardiac chest pain, a short course of omeprazole was found to be $78 \%$ sensitive and $85 \%$ specific when compared to a gold standard of a
(C) 2000 S. Karger AG, Basel

0257-2753/99/0174-0183\$17.50/0

Fax +416130612

E-Mail karger@karger.ch

www.karger.com
Accessible online at:

http://BioMedNet.com/karger positive ambulatory $\mathrm{pH}$ study or esophagitis on endoscopy [5]. When heartburn was studied as the index symptom, 1 week of omeprazole $20 \mathrm{mg}$ twice daily had a sensitivity of $75 \%$ but a specificity of only $55 \%$ [6]. The diagnosis of GERD is highly supportable in patients with suggestive symptoms that are relieved with acid suppression.

It is perhaps more important to be able to exclude complications of reflux disease if we are planning to empirically treat a patient with reflux symptoms. 'Warning symptoms' include dysphagia, chest pain and gastrointestinal bleeding. Even those symptoms are not specific. Routine reflux can cause dysphagia even without a structural lesion, while chest pain may be related to other causes in the upper abdomen and chest or may be functional. Despite the poor predictive value of warning symptoms, further investigation should be performed when they are present. The other major complication of GERD is Barrett's esophagus. The recent large population-based study from Scandinavia provided some guidance on who to investigate for Barrett's [7]. The refluxrelated factors that predicted the development of adenocarcinoma of the esophagus included frequency, severity and duration. Although not proven to save lives or to be cost-effective, it has been suggested that patients with long-standing, regular symptoms of GERD who are over the age of $40-50$ be screened for Barrett's esophagus and, if Barrett's is present, be entered into a surveillance program [8].

The current study evaluated yet another questionnaire's ability to predict reflux as documented by esophageal manometry, ambulatory $\mathrm{pH}$ testing and endoscopy [9]. Heartburn and regurgitation were predictive of 
an abnormal $\mathrm{pH}$ test and low lower esophageal sphincter pressure on manometry. This relationship was not perfect. Only $64 \%$ of patients with an abnormal pH test had heartburn and $62 \%$ had regurgitation, while $68 \%$ of patients with a low lower esophageal sphincter pressure had heartburn and 68\% had regurgitation. The only reflux complication evaluated in this study was stricture, which was predicted by a history of dysphagia. Those of us who participate in clinical trials evaluating therapies for GERD have similar experiences to this study. Despite our best history-taking skills, it is quite difficult to predict who will have an abnormal endoscopy or $\mathrm{pH}$ test. We do better when we accept either esophagitis or a $\mathrm{pH}$ test as evidence of reflux, but still find patients with an outstanding reflux history in whom we cannot document disease.
This could be due to false-negative endoscopies and $\mathrm{pH}$ tests, but is more likely related to the nonspecific nature of most esophageal symptoms. This is especially important when clinicians are evaluating patients for antireflux surgery. Objective evidence of reflux (esophagitis or abnormal $\mathrm{pH}$ testing) is mandatory prior to proceeding with antireflux surgery.

In summary, the diagnosis of GERD cannot universally be based on only symptoms nor can any one test be said to be the 'gold standard'. A carefully obtained history, therapeutic trial, ambulatory $\mathrm{pH}$ test, endoscopy and combinations of any (and sometimes all) of these maneuvers may be needed to confirm the diagnosis in any individual patient.

\section{References}

1 DeVault KR, Castell DO: Updated guidelines for the diagnosis and treatment of gastroesophageal reflux disease. Am J Gastroenterol 1999;94:1434-1442.

2 Tefera L, Fein M, Ritter MP, Bremner CG, Crookes PF, Peters JH, Hagen JA, DeMeester TR: Can the combination of symptoms and endoscopy confirm the presence of gastroesophageal reflux disease? Am Surg 1997;63:933936.

3 Carlsson R, Dent J, Bolling-Sternevald E, Johnsson F, Junghard O, Launitsen K, Riley S, Lundoll L: The usefulness of a structured questionnaire in the assessment of symptomatic reflux disease. Scand J Gastroenterol 1998;33: 1023-1029.
4 Johnsson F, Joelsson B, Gudmundsson K, Greiff L: Symptoms and endoscopic findings in the diagnosis of gastroesophageal reflux disease. Scand J Gastroenterol 1987;22:714-718.

5 Fass R, Fennerty MB, Offman JJ, Gralnek JM, Johnson C, Camargo E, Sampliner RE: The clinical and economic value of a short course of omeprazole in patients with noncardiac chest pain. Gastroenterology 1998;115:42-49.

6 Johnsson F, Weywadt L, Solhaug JH, Hernqvist $\mathrm{H}$, Bengtsson L: One-week omeprazole treatment in the diagnosis of gastro-oesophageal reflux disease. Scand J Gastroenterol 1998;33: 15-20.
7 Lagergren J, Bergstrom R, Lindgren A, Nyren $\mathrm{O}$ : Symptomatic gastroesophageal reflux as a risk factor for esophageal adenocarcinoma. N Engl J Med 1999;340:825-831.

8 Sampliner RE: Practice guidelines on the diagnosis, surveillance and therapy of Barrett's Esophagus. Am J Gastroenterol 1998;93:10281032.

9 Martinez-Serna T, Tercero F Jr, Filippi CJ, Dickason TJ, Watson P, Mittal SK, Tasset MR: Symptom priority ranking in the care of gastroesophageal reflux. A review of 1,850 cases. Dig Dis 1999;17:219-224. 